\title{
Research Trends and Application Prospects of CO2 Flooding Technology and Sequestration Technology
}

\author{
Chu tianshu,Zhao Dongfeng,Yuan Chen \\ Zhejiang Ocean University,Zhoushan,Zhejiang 316000,China \\ 1330963974@qq.com,409350641@qq.com,1138409976@qq.com
}

\begin{abstract}
Key words: $\mathrm{CO}_{2}$ flooding technology; $\mathrm{CO}_{2}$ sequestration technology; $\mathrm{CO}_{2}$ miscible pressure; current status of $\mathrm{CO}_{2}$ flooding; current situation of $\mathrm{CO}_{2}$ sequestration; prospects of $\mathrm{CO}_{2}$ flooding; prospects of $\mathrm{CO}_{2}$ sequestration
\end{abstract}

\begin{abstract}
CO}_{2}$ flooding technology and sequestration is one of the main ways to avoid global warming. The existing research both at home and abroad and the experimental results show that as an oil displacement agent, the $\mathrm{CO}_{2}$ injected in the reservoir can greatly improve the recovery efficiency of oil and gas. At the same time, the underground gas storage reservoirs which have good closed conditions, can achieve long-term geologic sequestration of $\mathrm{CO}_{2}$. In this paper, through the research of $\mathrm{CO}_{2}$ flooding and sequestration at home and abroad and the development trend of research dynamic analyse these two technologies application prospect in our country, put forward the necessity of developing $\mathrm{CO}_{2}$ flooding technology and sequestration technology in our country and some measures about these.
\end{abstract}

\section{Foreword}

Today,there are three major problems in the world: population, environment and resources. The deterioration of the earth's environment and the shortage of energy are hindering the sustainable development of mankind. The research shows that burying $\mathrm{CO}_{2}$ in oil reservoirs can not only improve oil and gas recovery rate, increase oil and gas reserves, but also achieve social benefits of carbon dioxide reduction. It is of great significance to solve environmental and resource problems. Therefore, the prospect of $\mathrm{CO}_{2}$ flooding technology and sequestration technology is very optimistic, which will play a vital role in resource shortage and emission reduction in China and the world at large.

\section{Research trends of $\mathrm{CO}_{2}$ flooding technology}

1.1Research trends of $\mathrm{CO}_{2}$ flooding technology abroad

In 1952, Whorton ${ }^{[1]}$ proposed a patent for $\mathrm{CO}_{2}$ flooding, making it possible to introduce $\mathrm{CO}_{2}$ flooding technology into oilfield development. Great progress has been made in reducing the pressure of carbon dioxide miscible. With miscible solvent, adding fluoride compounds, adding oil soluble surfactant, non-ionic surfactant, adding supercritical microemulsion, conducive to the displacement of $\mathrm{CO}_{2}$ foam system , are effective ways to reduce carbon dioxide minimum miscible pressure. At present, the best way to reduce the minimum mixing pressure is to add miscible copolytic solvent. Esso production and research company ${ }^{[2]}$ and shell oil company ${ }^{[3,4]}$ successively proposed to use tuol oil, a by-product of the paper industry, as the oil displacement agent for three times of oil production. Mobil ${ }^{[5]}$ in tall oil with supercritical $\mathrm{CO}_{2}$ alternating slug displacement study found that tall oil can not only effectively reduce the minimum miscible pressure, but there is 
to the benefit to improve hydrocarbon flow ratio, reduce gas channeling.

Djabbrah ${ }^{[6]}$ proposed in the patent that the addition of ethanol can effectively reduce the minimum miscibility pressure of $\mathrm{CO}_{2}$ flooding. The experimental results showed that the addition of ethanol with $0.1 \mathrm{PV}$ can reduce the minimum miscibility pressure by $40 \%$.

Bon ${ }^{[7]}$ found in the study of $\mathrm{CO}_{2}$ flooding in Cooper basin in central Australia that adding $\mathrm{C}_{5}+$ components can effectively reduce the minimum miscible pressure, and the inclusion of $\mathrm{CH}_{4}$ and $\mathrm{N}_{2}$ in $\mathrm{CO}_{2}$ is the most unfavorable.And the reservoir temperature has a certain influence on the minimum miscibility pressure, the higher the reservoir temperature,the minimum miscibility pressure is higher.

1.2 Domestic research trends of $\mathrm{CO}_{2}$ flooding technology

With the increasing global attention to the atmosphere polluted by $\mathrm{CO}_{2}$ emissions, the potential of $\mathrm{CO}_{2}$ injection has become greater and greater, and most of its projects have been studied.Our country attached great importance to $\mathrm{CO}_{2}$ emissions and resource utilization, specifically approved of the "973" project that greenhouse gases enhanced oil recovery efficiency of resource utilization and underground storage, also set up the national major projects and key projects of "863", for $\mathrm{CO}_{2}$ flooding technology, storage and utilization of various aspects has carried on the thorough research. China's oil reservoirs are buried deeply, most of which belong to continental deposits, and the minimum miscibility pressure of $\mathrm{CO}_{2}$ flooding is high, so most of them cannot achieve miscibility flooding under stratigraphic pressure. To improve oil displacement efficiency of $\mathrm{CO}_{2}$ and determine its influencing factors, formulate the relevant testing standards, the $\mathrm{CO}_{2}$ supercritical phase and the correlation of miscible pressure, further analysis of $\mathrm{CO}_{2}$ miscible conditions, using a special process or method, reduce the minimum miscible pressure, realization of miscible flooding ${ }^{[8]}$.

How to improve oil displacement efficiency is a key point of $\mathrm{CO}_{2}$ oil displacement technology. Under the condition of non-miscible phase flooding, the increase in the recovery rate of $\mathrm{CO}_{2}$ is relatively low, and the effect of non-miscible phase and miscible phase flooding is 2-5 times different, so the research mainly focuses on the improvement of miscible phase flooding technology. Peng Chao etc. ${ }^{[9]}$ in the interface tensiometer developed by the research of $\mathrm{CO}_{2}$, crude oil associated gas of oil and gas minimum miscible pressure pointed out that the influence of adding liquefied $\mathrm{CO}_{2}$ can effectively reduce the minimum miscible pressure. Zhang Guangdong ${ }^{[10]}$ selected methanol, ethanol, n-hexane, n-octane, petroleum ether, gasoline and four different light oils as miscible solvents

\subsection{Application prospect of $\mathrm{CO}_{2}$ flooding technology}

As countries around the world pay more attention to carbon dioxide emissions, carbon dioxide oil displacement technology is also developing at a high speed. $\mathrm{CO}_{2}$ flooding technology is the relative mature and has a wide prospect of production technology, which has more obvious advantages than traditional water drive oil, not only improve the oil recovery efficiency, but reduce the emissions of carbon dioxide in the atmosphere. For China, reservoir buried deeply in our country, most of the reservoir belongs to continental sedimentation, the minimum miscible pressure of $\mathrm{CO}_{2}$ flooding is higher,and most of the reservoir under the reservoir pressure can't realize the miscible flooding, so how to reduce the minimum miscible pressure is the problem that China's scholars need to solve . With the continuous optimization of process parameters by scholars in combination with the characteristics of China's oil reservoirs, the technology of $\mathrm{CO}_{2}$ flooding becomes more and more mature. It is believed that in the near future, carbon dioxide oil displacement technology will be widely used and highly valued in China. 


\section{Research trends of $\mathrm{CO}_{2}$ sequestration}

Carbon dioxide accounts for about 60 percent of all greenhouse gases, so reducing carbon dioxide emissions is a necessary measure to mitigate the greenhouse effect. Research shows that $\mathrm{CO}_{2}$ sequestration can meet the challenges brought by the growth of energy demand and the increase of $\mathrm{CO}_{2}$ emissions.

2.1 Development and current situation of $\mathrm{CO}_{2}$ sequestration technology

In 1990, Norway became the first country in the world to enact the $\mathrm{CO}_{2}$ emission tax ${ }^{[12]}$. The operators decided to inject the $\mathrm{CO}_{2}$ back into the stratum, which led to the buried project of $\mathrm{CO}_{2}$ in Sleipner brackish water layer. This is the world's first commercial scale project built entirely for the geological burial and storage of $\mathrm{CO}_{2}$, providing valuable experience for the geological sequestration and detection of $\mathrm{CO}_{2}$.

The Weyburn oilfield project in the United States is a successful case of the combination of enhanced oil recovery engineering and buried storage. The project has increased crude oil production by 800 cubic metres since 2000. Another more successful example is the Canadian injection of acidic gas to trap $\mathrm{CO}_{2}$. Because most of the acid gas is $\mathrm{CO}_{2}$, this project also plays a role of $\mathrm{CO}_{2}$ geological burial.

In recent years, injecting $\mathrm{CO}_{2}$ into deep ocean and deep stratum for storage is considered to be a very promising treatment or disposal method. Countries such as the US, Europe and Japan are spending a lot of money on the feasibility and technical research of this method, and have carried out real injection test work.

Canada, Japan and other countries have carried out research on the buried stock of deep salt water layer, exhausted gas reservoir and unrecoverable coal seam.

The European Union has launched the project "the potential assessment of carbon dioxide emissions from fossil fuels buried in Europe".

2.2 A brief description of the method of $\mathrm{CO}_{2}$ sequestration

Currently, there are three feasible $\mathrm{CO}_{2}$ sequestration methods: underground sequestration, ocean sequestration and forest and land ecological sequestration ${ }^{[13]}$. Underground sequestration of $\mathrm{CO}_{2}$ mainly includes depleted oil and gas reservoirs, deep brine reservoirs, unrecoverable coal seams and deep-sea sequestration. At present, the technology of ocean sequestration is not mature, and it is still in the exploratory stage. Forest and land ecological sequestration is the most economical method, but the required forest area is very large,so it's not the main method of burial.

The sequestration of depleted oil and gas reservoirs is realized by using $\mathrm{CO}_{2}$ to improve the recovery rate. The sequestration of deep brine layer is mainly to pass $\mathrm{CO}_{2}$ into the underground brine layer through the steam injection well, so as to dissolve the $\mathrm{CO}_{2}$. The slow chemical reaction between $\mathrm{CO}_{2}$ and underground minerals leads to the formation of carbonate and the sequestration of $\mathrm{CO}_{2}$. The deep coal seams sequestration uses the superior adsorption of $\mathrm{CO}_{2}$ to coal seams. There are two main ways to store $\mathrm{CO}_{2}$ in the deep sea: one is to inject $\mathrm{CO}_{2}$ into the deep sea using onshore pipelines or moving ships, and the other is to inject $\mathrm{CO}_{2}$ into the deep sea using vertical pipelines.

2.3 The application prospect of $\mathrm{CO}_{2}$ sequestration technology in China

Chinese research on $\mathrm{CO}_{2}$ storage has just started, but China has a huge potential for $\mathrm{CO}_{2}$ storage, which is affected by the neotectonic movement ${ }^{[14]}$.Chinese mainly large basin deposited multilayer assemblage sedimentary system, the number of layers is often more than ten or even dozens of layers,layer between the relative water-resisting layer or weak permeable layer form a relatively good sealing conditions, such as the Songliao basin and the Bohai bay basin, and coastal waters of main sedimentary basins such as the Bohai basin, North Yellow Sea basin. Taking the salty aquifer in the Songliao basin as an example, the theoretical storage capacity of $\mathrm{CO}_{2}$ in the salty aquifer in 
Songliao basin is $6916 \mathrm{Gt}$ and the effective storage capacity is $138 \mathrm{Gt}$. In addition, a number of offshore gas fields rich in $\mathrm{CO}_{2}$ have been discovered in Chinese oceans ${ }^{[15]}$, and a large amount of $\mathrm{CO}_{2}$ can also be buried by the method of buried deep brackish water layer of $\mathrm{CO}_{2}$ in offshore gas fields.Moreover our country is rich in coalbed methane resources, only Shanxi Jincheng mining area can reach 72 billion 800 million cubic meters.If $\mathrm{CO}_{2}$ can be exchanged and collected, the concentration of $\mathrm{CO}_{2}$ in the atmosphere can be reduced and a large amount of high quality energy can be extracted.It can be seen that $\mathrm{CO}_{2}$ sequestration in China has good geological conditions and application prospects.

\section{Conclusion}

Extensive research has been carried out on the technology of $\mathrm{CO}_{2}$ flooding and sequestration in the world, but there are still many problems to be solved. China is facing the problem of energy shortage and greenhouse effect. Therefore,it's necessary and urgent to develop the technology of $\mathrm{CO}_{2}$ flooding and sequestration. China should vigorously promote $\mathrm{CO}_{2}$ flooding and sequestration technology, relevant industries to carry out research and technical attack. Also should introduce the relevant preferential policies to develop and coordinate related industry development plan, promote the adjustment of industrial structure, strengthen international exchanges and cooperation,absorb foreign advanced technology and take the path of production-teaching-research combination. Make technology of $\mathrm{CO}_{2}$ flooding and sequestration technology put into practical use in China at an early date to promote green and low-carbon development and contribute to global warming.

\section{References}

[1]WHORTON L P,BROWNSCOMBE E R,DYES A B.Method for Production Oil by Means of Carbon Dioxide:US,2623596[P].1952-12-30.

[2] Esso Production Research Company.Miscrible Drive Oil Recovery Process:US.3497007[p].1970-02-24.

[3]Shell oil Company.Digested Alkaline Tall Oil Pitch soap composition :US,3892668[p].1975-07-01.

[4]Shell Oil Company.Process of Displacing Oil in Subterranean Reservoir Employing Aqueous Surfactant Systems:US,3943059[P].1976-03-09.

[5]Mobil Oil Corporation.Tall Oil as Additive in Gas Drive Hydrocarbon Oil Recovery :US,4736793[p].1988-04-12.

[6]DJABBARAH N F.Miscible Oil Recovery Process Using Carbon Dioxide and Alcohol:US,4899817[p].1990-02-13.

[7]BON J,SARMA H K,THEOPHILOS A M.An Investigation of Minimum Miscibility Pressure for CO2-Rich Injection Gases with Pentanes-Plus Fraction [C]//SPE International Improved Oil Recovery Conference in Asia Pacific,5-6 December,2005,Kuala Lumpur,Malaysia.

[8] Guo Ping, Yuan Zhiwang, Liao Guangzhi. Current situation and enlightenment of gas injection flooding technology [J]. Natural gas industry, 2009.29 (8) : 92-96.

[9] Peng Chao, Lliu Jianyi, Zhang Guangdong, et al. New methods to reduce CO2 oil displacement MMP [J]. Journal of Chongqing university of science and technology: natural science edition, 2012,14 (1) : 48-51.

[10] Zhang Guangdong, Liu Jianyi, Liu Yanli, et al. Study on reducing CO2 flooding miscible pressure by miscible solvent method [J]. Special oil and gas reservoir, 2013,20 (2) : 115-117. 
[11] Southwest petroleum university. A method for reducing the minimum mixing pressure between CO2 and crude oil by miscible flooding: China, 102337874 A[P].2012-02-01.

[12]Yang Yongzhi.Study on the evaluation system of CO2 geological burial and oil recovery[C].

[13]Jiang Huaiyou.Current situation and prospect of global warming and carbon dioxide storage[J].Journal of the ancient geography,2008,03(10)324-328.

[14]Jiang Huaiyou.Current situation and prospect of world carbon dioxide storage technology[J].Chinese energy,2010,06(32)28-32.

[15]Jing Fengjiang.Application and consideration of carbon dioxide storage technology in offshore gas field in China[J].Evaluation and development of oil and gas reservoir,2011,05(1)21-28.

Foundation project:Founding support project of the new entrepreneurship training program for university students at the national level 201710340020 